\title{
P96 Soluble Receptor for Advanced Glycation End-products Independently Influenced Individual Age-dependent Increase of Arterial Stiffness
}

\author{
Július Gelžinskýt \\ Medical Faculty in Pilsen, Charles University, Czech Republic
}

\section{ABSTRACT}

Background: Soluble receptors for advanced glycation end-products (sRAGEs) have been suggested to have a protective role neutralizing the advanced glycation end-products (AGEs) and their pathological effect on vessel walls. We aimed to investigate the association between circulating concentrations of sRAGEs and dynamic of arterial wall stiffening as a manifestation of vascular ageing in general population.

Methods: In a prospective cohort study, we longitudinally followed 530 general-population-based subjects (subsample of Czech post-Monica study). Aortic pulse wave velocity (PWV) was measured twice (at baseline and after $\approx 8$ years of follow-up) using a Sphygmocor device (AtCor Medical Ltd.) and intra-individual change of PWV per year ( $\triangle \mathrm{PWV} /$ year) was calculated. Concentrations of sRAGE were assessed at baseline by ELISA methods (R\&D Systems).

Results: Average $\triangle \mathrm{PWV} /$ year significantly increased across the sRAGE quintiles $(p=0.0008)$ and drop by one sRAGE quintile was associated with $\approx 21 \%$ increase in the relative risk of accelerated age-dependent stiffening ( $\triangle \mathrm{PWV} /$ year $\geq 0.2 \mathrm{~m} / \mathrm{sec}$ ). In a categorized manner, subjects in the bottom quintile of sRAGE $(<889.74 \mathrm{pg} / \mathrm{mL})$ had fully adjusted odds ratio of accelerated stiffening 1.72 (95\% CI: $1.06-2.79), p=0.028$, while those with high sRAGE concentrations $(\geq 1695.2 \mathrm{pg} / \mathrm{mL})$ showed opposite effect [with odds ratio 0.55 (95\% CI: 0.33-0.90), $p=0.017$ ].

Conclusion: Circulating status of sRAGE independently influenced individual progression of arterial stiffness overt time. This finding strongly supports hypothesis, that high sRAGE have protective role against vascular ageing.

(c) 2019 Association for Research into Arterial Structure and Physiology. Publishing services by Atlantis Press International B.V. This is an open access article distributed under the CC BY-NC 4.0 license (http://creativecommons.org/licenses/by-nc/4.0/). 